\title{
Gestão da aprendizagem em tempos de Ideb: percepções dos docentes
}

\author{
Learning management in Ideb times: perceptions of teachers \\ Gestión del aprendizaje en tiempos de ldeb: percepciones de los maestros \\ SOFIA LERCHE VIEIRA \\ ELOISA MAIA VIDAL \\ JAANA FLAVIA FERNANDES NOGUEIRA
}

\begin{abstract}
Resumo: Problematizando as repercussões em torno da divulgação dos resultados do Índice de Desenvolvimento da Educação Básica (Ideb) 2013, este artigo analisa as políticas de avaliação de larga escala, a gestão e o trabalho docente neste contexto. Visando compreender se e como os professores se posicionam face às dificuldades de aprendizagem dos alunos, são analisadas algumas respostas do Questionário do Professor dos $5^{\circ}$ e $9^{\circ}$ anos do Ensino Fundamental, integrante da Prova Brasil 2011. Considerações finais buscam estabelecer nexos entre os tópicos tratados.
\end{abstract}

Palavras chave: Tempos de Ideb; avaliação de larga escala; séries finais do ensino fundamental; percepções docentes; dificuldades de aprendizagem.

Abstract: This paper analyzes large scale evaluation policies, the management and the teaching work discussing the repercussions around the dissemination of the results of the 2013 Indice de Desenvolvimento da Educação Básica (Ideb) Basic Education Development Index (Ideb). The aim is to understand whether and how teachers face their students' learning difficulties analyzing some Teacher Questionnaire responses of the 2011 Brazilian national exam named Prova Brasil which is applied in the 5th and 9th years of elementary school. Final considerations seek to establish links between the topics.

Keywords: Basic education development Index (Ideb) times; Brazilian large scale evaluation; final grades of elementary and lower secondary education; teachers' perceptions; learning difficulties.

Resumen: Problematizando las repercusiones en torno a la divulgación de los resultados del Índice del Desarrollo de la Educación Básica (Ideb) 2013, este artículo analisa las políticas de evaluación de amplia escala, la gestión y el trabajo docente en este contexto. Buscando comprender si y como los profesores se posicionan ante las dificultades de aprendizado de los alumnos son analisadas algunas respuestas del Questionario del Profesor de $\operatorname{los} 5^{\circ}$ y $9^{\circ}$ años de la Enseñanza Fundamental, integrante de la Prueva Brasil 2011. Consideraciones finales buscan establecer nexos entre los tópicos tratados. 
Palabras clave: Tiempos do Ideb; evaluación de amplia escala; series finales de la enseñanza fundamental; percepciones docentes; dificultades de aprendizaje.

\section{INTRODUÇÃO}

As políticas de avaliação de larga escala que vêm se instalando no cotidiano da gestão escolar, desde a segunda metade da década de noventa do século XX no Brasil, têm suscitado novas formas de organização do trabalho docente. O presente artigo discute impactos de tais políticas na escola, aprofundando características desse novo modo de produção e de gestão da aprendizagem naquilo que alguns estudos têm denominado de tempos de Ideb (MACEDO, 2011, CARDOSO, 2011 e VIDAL \& VIEIRA, 2014), contexto sobre o qual a presente reflexão se detém. O ensaio procura desenvolver o argumento de que o Ideb (Índice de Desenvolvimento da Educação Básica) tem se transformado em um grande indutor do trabalho de gestores e professores, daí porque, como síntese toma-se o momento vivido pela política educacional e pela escola como tempos de Ideb. Além de trazerem uma nova lógica para a organização e a gestão da escola, esses tempos têm contribuído para novas configurações e ritmos no trabalho docente.

\section{RESULTADOS DO IDEB - UMA SURPRESA ANUNCIADA?}

Quando foi divulgado o Ideb 2013, os resultados do $9^{\circ}$ ano do ensino fundamental surpreenderam a imprensa em geral, políticos e estudiosos. O chamado efeito onda, que seria resultante da melhoria continua dos resultados de aprendizagem do $5^{\circ}$ ano desde 2005 , não chegou à última etapa do ensino fundamental. $\mathrm{O}$ que teria acontecido? As crianças estariam obtendo melhores níveis de desempenho nos cinco primeiros anos do ensino fundamental, mas não evoluíam na aprendizagem de modo a dar continuidade a esse processo nos quatro anos seguintes? Onde estaria a fonte de dificuldades?

Buscando elementos para responder tais indagações este artigo discute questões relacionadas à política e à gestão no contexto da avaliação de larga escala, procurando, ao mesmo tempo, explorar informações coletadas no Questionário do Professor, um dos questionários contextuais integrantes da Prova Brasil 2011, particularmente algumas que permitem elucidar como os professores percebem as dificuldades de aprendizagem de seus alunos. A escolha desse corpus de análise articula-se a incursões anteriores sobre a matéria (VIDAL; VIEIRA, 2011). Em 2013, Rabelo afirmaria, baseado na série histórica do Saeb 1997 - 2005, que 
os resultados de desempenho dos alunos do $8^{\mathrm{a}} / 9^{\circ}$ ano estavam estagnados desde 1999 (p. 38).

Além de avaliar, de forma bastante ampla, o desempenho dos alunos nas disciplinas de Língua Portuguesa e Matemática nos $5^{\circ}$ e $9^{\circ}$ anos do ensino fundamental em escolas públicas, a Prova Brasil aplica junto a diretores, professores das disciplinas, alunos e escolas, questionários contextuais. Estes procuram captar informações sobre o "contexto socioeconômico e as características de alunos, professores, diretores e escolas, bem como sobre as condições em que ocorrem os processos de ensino e aprendizagem" (INEP, 2013).

Segundo o Inep (2002), “os questionários contextuais desempenham o papel de oferecer fatores explicativos para a modelagem do desempenho dos alunos, medida pelos instrumentos cognitivos" (p. 45). A cada edição, os questionários sofrem alterações ${ }^{1}$ e desempenham importante papel na "produção de indicadores de qualidade das condições de escolarização e a modelagem de como esses indicadores se distribuem entre alunos de origem sociodemográfica distinta" (RAUDENBUSH, RANDALL e CHEONG, 1999 apud INEP, 2002, p. 46).

Conforme já referido, este artigo toma algumas questões do Questionário do Professor em consideração, na expectativa de verificar como os docentes percebem os problemas relativos à aprendizagem de seus alunos. Antes, porém, é oportuno, situar a avaliação de larga escala e suas interfaces com a política e a gestão escolar.

\section{AVALIAÇÃO DE LARGA ESCALA, POLÍTICA E GESTÃO}

A avaliação de larga escala começa a chegar ao Brasil pelo final dos anos 1980, quando o governo federal e alguns governos estaduais (BROOKE; CUNHA, 2010) deflagram iniciativas diversas visando aferir resultados de estudantes em provas aplicadas em escolas da rede pública. Foi neste contexto que surgiu o Sistema de Avaliação da Educação Básica (Saeb), desenvolvido pelo Ministério da Educação, que por seu alcance e abrangência nacional será aqui focalizado por atingir todas as unidades da federação.

Tal como concebido originalmente o Saeb constituía-se em "um sistema de avaliação amostral, operacionalizado a cada dois anos com a finalidade

\footnotetext{
${ }^{1}$ Com o objetivo de aprimorar a qualidade das informações de contexto produzidas pelos questionários do Saeb e, ainda, possibilitar a exploração de novos aspectos da realidade educacional, cuja análise ora se mostra importante, a Diretoria de Avaliação da Educação Básica do Inep desenvolveu, no decorrer do ano de 2003, a revisão dos questionários utilizados nas aplicações do Saeb em 1995, 1997, 1999 e 2001 (INEP, 2006, p. 172).
} 
principal de avaliar a qualidade, equidade e eficiência do ensino e da aprendizagem no âmbito do Ensino Fundamental e do Médio" (VIEIRA, 2008b, p. 115).

Tendo sido gradativamente ampliado, em 2005 passou a configurarse como um sistema composto por duas avaliações: Avaliação Nacional da Educação Básica (Aneb) e a Avaliação Nacional do Rendimento no Ensino Escolar (Anresc), também conhecida como Prova Brasil, cuja primeira edição foi realizada naquele mesmo ano. Em 2013, o Saeb passa a incorporar uma terceira avaliação, a Avaliação Nacional de Alfabetização (Ana), realizada anualmente de forma censitária, com alunos do $3^{\circ}$ ano do ensino fundamental das escolas públicas, avaliando os níveis de alfabetização e letramento em Língua Portuguesa e alfabetização Matemática.

A Prova Brasil permitiu que estados, municípios e escolas públicas de ensino fundamental pudessem acompanhar seus resultados. Na prática, tal medida contribuiu para uma mudança no percurso das políticas de avaliação de larga escala no país. A divulgação dos indicadores de desempenho gradativamente instituiu um ambiente propício ao surgimento de uma cultura de responsabilização, conforme se destaca adiante.

A esta mudança veio a somar-se a criação do Índice de Desenvolvimento da Educação Básica (Ideb), em 2007, com o objetivo de "medir a qualidade do aprendizado nacional e estabelecer metas para a melhoria do ensino" (http:// portal.mec.gov.br $/$ index.php?Itemid $=336>$ Acesso em: 10 ago. 2014)

Conforme observado,

A aplicação da fórmula do Ideb a estados, municípios e escolas incorpora dados de rendimento escolar (taxa de aprovação) e resultados da Prova Brasil. Desde então, sua divulgação tem sido acompanhada com interesse por parte de formuladores e executores de políticas educacionais, o que constitui evidência de sua relevância para a aferição do desempenho escolar de estudantes da Educação Básica e seu caráter estratégico na definição de políticas de melhoria da qualidade da educação. A mobilização e destaque que os meios de comunicação têm oferecido à divulgação dos resultados do Ideb tem desempenhado papel relevante junto à opinião pública e contribuído, de forma expressiva, para a popularização da agenda educacional junto a sociedade em geral (VIEIRA; VIDAL, 2013, p. 22).

O Ideb tem facilitado a implantação daquilo que vem sendo chamado de política de responsabilização ou accountability em educação. Segundo Cerdeira e Almeida (2013)

$\mathrm{Na}$ lógica da responsabilização educacional, os profissionais da educação são considerados corresponsáveis pelo desempenho dos alunos (BROOKE, 2006). Neste modelo, os resultados escolares passaram a ser divulgados publicamente, o 
que gerou o rankeamento das escolas e maior exposição de professores, gestores escolares e gestores de redes de ensino (p. 1)

Com efeito, este é um tema polêmico tanto no âmbito governamental, quanto sindical e acadêmico. Há posições divergentes a respeito da matéria. Enquanto uns se manifestam a favor "do aprimoramento das políticas e da criação de uma cultura avaliativa" (BROOKE, 2006 e 2008; SOUZA, 2007); outros, como Souza; Oliveira (2003), Freitas (2007), Coelho (2008), Barriga (2009) e Casassus (2009) são críticos desta posição.

Os argumentos favoráveis defendem "que os sistemas de avaliação possibilitam o desenvolvimento de políticas públicas e ações pedagógicas que contribuem para o monitoramento da aprendizagem e a elevação da qualidade do ensino" (VIANNA, 2003; ALAVARSE; MACHADO; BRAVO, 2012) ou por "permitirem a identificação e análise das consequências das políticas já implementadas e seus efeitos no desempenho discente" (FRANCO; ALVES e BONAMINO, 2007).

Os argumentos contrários às políticas de responsabilização, por sua vez, destacam

os efeitos negativos como a imposição dessas políticas pelo governo, sem maiores esclarecimentos; o estabelecimento de rankings escolares; o fato das avaliações não medirem o real trabalho feito na sala de aula; o engessamento do currículo e das práticas docentes, sobretudo nas disciplinas de português e matemática; e a responsabilização do professor, pois não se sentem amparados pelas secretarias e coordenadorias de educação, além de enfrentarem sérios problemas sociais e de violência nas escolas. As críticas também evidenciam a padronização das provas e os usos inadequados dos resultados pelos gestores educacionais (CERDEIRA; ALMEIDA, 2013, p.2).

Segundo as autoras, há de se destacar ainda, os "efeitos perversos" das políticas de responsabilização (RAVITCH, 2010), em particular

as que estabelecem prêmios e punições e que podem provocar o aumento da desigualdade intraescolar, a saber: foco no treinamento para responder as questões da prova em detrimento da aprendizagem; exagero de provas e simulados que causam a perda de aulas; professores e diretores podem deliberadamente investir nos alunos que tem chance de alcançar as metas (notas) estipuladas, "abandonando" os grupos extremos (os melhores e os piores); estímulo aos piores alunos para faltarem à prova; etc (IDEM).

Qual o interesse desse debate para o tema de nossa reflexão? A gestão das políticas de avaliação de larga escala é feita pelo que poderia ser denominado 
de "cadeia produtiva" da educação, envolvendo em cada etapa atribuições e especificidades, desde o Ministério da Educação (MEC), passando pelas secretarias estaduais e municipais, até chegar nas escolas. Cada uma dessas etapas envolve um imenso contingente de instituições e sujeitos que se dedicam a esse processo no qual os professores vêm ocupando papel de destaque.

Como nas demais instâncias pelas quais circula, a avaliação de larga escala aporta na escola sob a forma de produto e de processo. Enquanto produto a avaliação assume o formato de provas - que a escola não pediu ou sequer foi consultada para aplicar - e de resultados obtidos por seus alunos, os quais por sua vez impactam de diversas maneiras o cotidiano escolar. Enquanto processo, em maior ou menor grau, a avaliação de larga escala passa a ser incorporada à vida da escola de inúmeras maneiras e em diferentes dimensões do currículo. Os professores, por sua vez, são considerados os principais responsáveis pela implementação dos processos e pelos produtos obtidos, nesse caso, em forma de resultados de aprendizagem dos alunos.

Algumas escolas elegem as avaliações de larga escala como fonte permanente de inspiração para o seu trabalho; outras preferem prosseguir fazendo o que sempre fizeram ou até mesmo ignorá-las. Fato é que ano a ano e passo a passo tem se tornado mais difícil fazer de conta que as avaliações externas não existem. Isto porque a escola e seus docentes não apenas são cobrados, como também premiados (e cada vez mais!) e mesmo punidos por seu desempenho.

\section{IMPACTOS SOBRE O TRABALHO DOCENTE}

Tendo examinado a política de avaliação de larga escala e as etapas de sua gestão, chegamos, por fim, ao tema central da análise - o trabalho docente. Algumas perguntas aqui se colocam: como todos esses componentes da política e de sua gestão se combinam e atingem os professores? Seus impactos sobre eles são semelhantes para todos ou diferenciados por segmentos? $\mathrm{O}$ trabalho docente permanece o mesmo, ou é alterado pelas novas circunstâncias que passam a se fazer presentes na dinâmica da escola? Que novos desafios se colocam para o fazer pedagógico dos professores diante desse contexto?

Em um ambiente cada vez mais propício à transparência pública, sob o advento de legislação específica (BRASIL. Lei no 12.527/11) e de portais que se disseminam por todo país ${ }^{2}$, "prestar contas" passa a ser um valor cada vez mais presente na dinâmica político-social e, consequentemente, nos sistemas de ensino e suas respectivas redes escolares.

\footnotetext{
${ }^{2}$ Ver, a propósito: <portaldatransparencia.gov.br>
} 
A prestação de contas em si não é um valor negativo; ao contrário. A escola enquanto um bem público precisa dizer a que veio à sociedade que a criou e a mantém, que, via de regra, deve se expressar pelo sucesso na aprendizagem dos alunos. $\mathrm{O}$ problema reside nos usos correlatos que vem se fazendo das avaliações. Refere-se ao modo como as políticas de prestações de contas são veiculadas pelos sistemas de ensino. Cria-se toda uma parafernália gerencial e política em torno das provas, aí incluindo o ranqueamento (ranking) entre sistemas e instituições.

Neste contexto, aquilo que deveria representar um diagnóstico de um momento da vida escolar (a avaliação externa), passa a ser vivido como se fosse sua essência. Sistemas e escolas passam a viver sob o signo da avaliação de larga escala, atendendo a uma lógica imposta de fora para dentro. De instituição comprometida com a formação para a cidadania, veiculação e transmissão do saber, a escola passa a se configurar como uma pequena linha de montagem, onde gestores, professores e estudantes passam a valer pelos bens que produzem sob a forma de resultados.

Algumas perguntas emergem neste contexto. Em primeiro lugar, como todos esses componentes da política e de sua gestão se combinam e atingem os professores? As políticas de avaliação de larga escala têm efeitos diretos sobre a escola e o trabalho docente. Se antes era possível manter uma lógica de funcionamento gerida internamente, em que gestores e professores podiam decidir sobre o que fazer e como fazer, respeitando a realidade local; hoje, não mais. O trabalho escolar, ainda que mantenha muitos elementos de seu modo de produção anterior, foi profundamente alterado pelas orientações advindas de tais políticas.

A segunda indagação diz respeito aos efeitos das políticas de avaliação sobre os docentes. Seus efeitos são semelhantes para todos ou diferenciados por segmentos? A resposta a esta questão poderia ser resumida nos seguintes termos: se a escola é impactada como um todo, os docentes são atingidos de forma diferenciada, a depender das disciplinas e das séries onde atuam. Aqui muitas questões se colocam, a começar pelo gerenciamento do currículo.

Em tempos de Ideb o maior destaque é para as disciplinas que se constituem em objetos, por excelência das provas de Língua Portuguesa e de Matemática, sendo que as demais disciplinas passam a ocupar um lugar hierarquicamente inferior em termos de carga horária e importância epistemológica no currículo. Tal tendência, detectada por alguns estudos no campo há alguns anos (VIDAL; VIEIRA, 2011 e 2014), tem se acentuado com o passar do tempo e com o processo de enraizamento da avaliação de larga escala no chão da escola. Assim como algumas disciplinas são privilegiadas em termos 
de currículo, do mesmo modo, as séries selecionadas para aplicação das provas tendem a receber maior atenção que as demais. Embora não seja uma regra e não ocorra em todas as escolas, vem se criando uma hierarquia entre docentes que se instaura a depender de suas áreas de formação e atuação e das séries onde trabalham.

As considerações acerca das políticas, da gestão e do trabalho docente oferecem elementos para situar o contexto onde os docentes se movimentam. Feito isto, é oportuno examinar como estes se colocam face às dificuldades de aprendizagem de seus alunos. É hora, pois, de examinar o conteúdo do Questionário do Professor da Prova Brasil que indaga sobe a matéria.

\section{ANALISANDO RESPOSTAS DOS DOCENTES À PROVA BRASIL 2011}

A expectativa frustrada de que a melhoria nos resultados de desempenho dos alunos do $5^{\circ}$ ano se alastraria por meio do efeito onda aos alunos do $9^{\circ}$ ano, provocando melhoria de resultados de aprendizagem ao fim do ensino fundamental, foi o que motivou uma investigação mais detalhada acerca dos conteúdos presentes no Questionário do Professor da Prova Brasil.

Em tempos de Ideb, os professores têm sido os personagens no processo educacional a quem mais tem se dirigido críticas e responsabilidade sobre o desempenho dos alunos em avaliações de larga escala. Tal fato é decorrente de estudos internacionais que reforçam o argumento de que os docentes são os principais responsáveis pelos resultados de aprendizagem dos alunos (LEITHWOOD et al, 2006, VOLANTE, 2012; MCKINSEY; COMPANY, 2007 e 2010; PEARSON, 2012).

No Brasil, estudos realizados pelo Ministério da Educação e por instituições não governamentais mostram que a associação entre resultados de aprendizagem dos alunos e responsabilização dos professores se faz presente, embora ainda não se disponha de dados mais objetivos. É o que se observa, por exemplo, no estudo de Parandekar et al (2008) quando afirma que "professores atuantes, capacitados e compromissados com uma educação de qualidade" são aspectos que contribuem para a melhoria das políticas educacionais municipais. Outra pesquisa realizada pelo Inep (2010) aponta o elevado senso de responsabilidade profissional dos docentes em relação ao sucesso dos alunos e preservação e otimização do tempo escolar como determinantes para a melhoria do desempenho. 
Este artigo focaliza a base de dados referente ao Questionário do Professor, utilizando os microdados ${ }^{3}$ da Prova Brasil 2011, aplicado a 304.412 docentes dos quais 150.972 atuam no $5^{\circ}$ ano e 153.440 no $9^{\circ}$ ano. O instrumento contém 152 perguntas, agrupadas, a partir de critérios dos autores, em seis grandes blocos: perfil profissional, livro didático, práticas pedagógicas, dificuldades de aprendizagem, violência na escola, participação na gestão escolar. Tais questões podem ser reagrupadas em outras subcategorias ou mesmo analisadas individualmente, e representam um acervo valioso sobre o que pensam ou expressam os docentes acerca de vários assuntos. Excluindo o Censo Escolar da Educação Básica, aplicado anualmente pelo Inep, e que nos últimos anos vem coletando informações mais detalhadas sobre docentes, essa pode ser considerada a maior base de dados ${ }^{4}$ acerca de professores de Língua Portuguesa e Matemática, disponível para pesquisadores, em anos recentes.

O Questionário do Professor 2011 não permite identificar o número de docentes por disciplina, embora exista um bloco de questões dirigidas especificamente para os professores de Língua Portuguesa (questões 133 a 141) e outro para os de Matemática (questões 142 a 152), o que permite estimar a partir do quantitativo de respondentes, com boa aproximação, o número de docentes de cada disciplina. Para confirmar a estimativa, buscaram-se os dados do Questionário do Professor da Prova Brasil 2007 que identifica a disciplina do docente e descobriu-se que as quantidades são praticamente as mesmas, ou seja, tanto no $5^{\circ}$ ano como no $9^{\circ}$ ano, a quantidade de docentes de Língua Portuguesa e de Matemática são equivalentes.

\section{ELEMENTOS DE UM PERFIL PROFISSIONAL}

Antes de investigar aspectos relacionados às dificuldades de aprendizagem dos alunos, indicadas pelos professores de $5^{\circ}$ e $9^{\circ}$ anos, procurouse observar alguns dados sobre o perfil ${ }^{5}$ desses profissionais. Dos 150.972 professores do $5^{\circ}$ ano, 48.321 (32\%) não preencheram o questionário e 102.663 o fizeram de forma parcial ou total, sendo que tal fato dá uma média de respostas em branco da ordem de 40,1\%. No caso dos docentes de $9^{\circ}$ ano, dos 153.440 respondentes, foram identificados $22.120(14,4 \%)$ questionários em branco e

\footnotetext{
3 Os microdados encontram-se disponíveis em http://portal.inep.gov.br/basica-levantamentos-acessar.

4 Importante informar que a Prova Brasil 2011 foi a que atingiu o maior número de escolas, diretores e professores. Enquanto a Prova Brasil 2007 aplicou questionários a 292.828 docentes, a de 2009 aplicou a 216.495, a de 2011 abrangeu 304.412 professores.

${ }^{5}$ Os autores selecionaram parte das informações contidas nas questões 1 a 36 para analisar o perfil profissional dos professores. Essa análise se restringiu a simples cálculos de percentagens, sem maiores inferências estatísticas e sem esgotar, também, a quantidade de dados disponíveis.
} 
131.308 preenchidos parcial ou total, com uma média de respostas em branco da ordem de $22,3 \%$.

A análise a seguir toma como referência apenas a quantidade dos docentes que respondeu o questionário e cada uma das perguntas, excluindo aqueles que responderam em branco, pelo fato desse tipo de resposta não fornecer objetivamente nenhuma informação acerca das alternativas propostas no questionário. No intuito de investigar elementos do perfil dos docentes que pudessem dar pistas sobre os resultados de desempenho dos estudantes nas provas aplicadas no $5^{\circ}$ e $9^{\circ}$ anos, a análise procura destacar elementos comparativos entre os professores.

O quadro 1 mostra dados relativos a sexo dos docentes que atuam no $5^{\circ}$ e $9^{\circ}$ ano do ensino fundamental.

\section{Quadro 1 - sexo dos professores participantes da prova Brasil 2011}

\begin{tabular}{|l|c|c|c|c|}
\hline Sexo & $\mathbf{5}^{\circ}$ ano & $\mathbf{0}$ & $\mathbf{9}^{\circ}$ ano & $\mathbf{\%}$ \\
\hline Masculino & 9.776 & $9,9 \%$ & 36.024 & $28,2 \%$ \\
\hline Feminino & 89.180 & $90,1 \%$ & 91.826 & $71,8 \%$ \\
\hline Total & $\mathbf{9 8 . 9 5 6}$ & $\mathbf{1 0 0 , 0} \%$ & $\mathbf{1 2 7 . 8 5 0}$ & $\mathbf{1 0 0 , 0 \%}$ \\
\hline
\end{tabular}

Os dados mostram que no $5^{\circ}$ ano prevalecem docentes do sexo feminino, com apenas $9,9 \%$ destes do sexo masculino, enquanto no $9^{\circ}$ ano, $28,2 \%$ dos professores são do sexo masculino, a maioria de Matemática. Esse dado está associado à cultura brasileira que, durante muitas décadas, depositou na professora primária a responsabilidade pelo ensino das primeiras letras (DERMATINI, 1993; LOURO, 1997; NARVAES; OLIVEIRA, 1999, WERLE, 2005 e, DRABACH; FREITAS, 2012).

Os dados do quadro 2 mostram as faixas de idade em que se situam os professores envolvidos na pesquisa.

Quadro 2 - idade dos professores participantes da prova Brasil 2011

\begin{tabular}{|l|c|c|c|c|}
\hline Idade & $\mathbf{5}^{\circ}$ ano & $\mathbf{\%}$ & $\mathbf{9}^{\circ}$ ano & $\mathbf{0}$ \\
\hline Até 24 anos & 2.360 & $2,4 \%$ & 4.630 & $3,6 \%$ \\
\hline De 25 a 29 anos & 8.727 & $8,9 \%$ & 14.696 & $11,6 \%$ \\
\hline De 30 a 39 anos & 34.379 & $35,0 \%$ & 44.543 & $35,0 \%$ \\
\hline De 40 a 49 anos & 37.044 & $37,7 \%$ & 42.951 & $33,8 \%$ \\
\hline De 50 a 59 anos & 9.574 & $9,8 \%$ & 12.228 & $9,6 \%$ \\
\hline
\end{tabular}




\begin{tabular}{|l|c|c|c|c|}
\hline Idade & $\mathbf{5}^{\circ}$ ano & $\mathbf{0}$ & $\mathbf{9}^{\circ}$ ano & $\mathbf{0}$ \\
\hline 55 anos ou mais & 6.076 & $6,2 \%$ & 8.110 & $6,4 \%$ \\
\hline Total & 98.160 & $100,0 \%$ & 127.158 & $100,0 \%$ \\
\hline
\end{tabular}

Nesse caso, registram-se diferenças entre os docentes nas faixas de 25 a 29 anos, com $8,9^{\circ} \%$ atuando no $5^{\circ}$ ano e $11,6 \%$, no $9^{\circ}$ ano e na faixa de 40 a 49 anos com 37,7\% dos docentes no $5^{\circ}$ ano e $33,8 \%$ no $9^{\circ}$ ano, evidenciando que no $9^{\circ}$ ano é mais frequente professores em início de carreira, com menos experiência na docência.

No que se refere a dados sobre formação profissional, os docentes do $9^{\circ}$ ano com graduação em cursos presenciais chegam a 89,8\% enquanto os do $5^{\circ}$ ano são $74,9 \%$; sendo que $11,4 \%$ e $9,4 \%$ dos docentes do $5^{\circ}$ ano realizaram seus cursos nas modalidades semipresenciais e a distância, fato que só ocorreu para 6,2\% e 3,4\% dos docentes do $9^{\circ}$ ano. Outro aspecto que chama a atenção no que tange à formação diz respeito à pósgraduação. O quadro 3 apresenta os dados dos docentes que responderam a pergunta do Questionário - cerca de $1 / 3$ dos professores de $5^{\circ}$ ano e $1 / 2$ dos de $9^{\circ}$ ano.

\section{Quadro 3 - área temática da pós-graduação dos professores participantes da prova Brasil 2011}

\begin{tabular}{|l|c|c|c|c|}
\hline $\begin{array}{c}\text { Indique qual a área temática do } \\
\text { curso de pós-graduação }\end{array}$ & $\mathbf{5}^{\circ}$ ano & $\mathbf{\%}$ & $\mathbf{9}^{\circ}$ ano & $\mathbf{\%}$ \\
\hline Educação, enfatizando alfabetização & 9.762 & $18,9 \%$ & 1.877 & $2,3 \%$ \\
\hline $\begin{array}{l}\text { Educação, enfatizando linguística e/ou } \\
\text { letramento }\end{array}$ & 6.124 & $11,9 \%$ & 22.537 & $27,9 \%$ \\
\hline $\begin{array}{l}\text { Educação, enfatizando educação } \\
\text { matemática }\end{array}$ & 1.946 & $3,8 \%$ & 22.795 & $28,2 \%$ \\
\hline Educação - outras ênfases & 32.126 & $62,3 \%$ & 29.675 & $36,8 \%$ \\
\hline Outras áreas que não a educação & 1.586 & $3,1 \%$ & 3.858 & $4,8 \%$ \\
\hline Total & 51.544 & $100,0 \%$ & 80.742 & $100,0 \%$ \\
\hline
\end{tabular}

Observa-se que prevalece entre os docentes a formação de pós-graduação em outras áreas educacionais $\left(62,3 \%\right.$ - $5^{\circ}$ ano e $36,8 \%$ - $9^{\circ}$ ano) em detrimento de formações mais dirigidas para suas áreas de atuação, no caso alfabetização para professores do $5^{\circ}$ ano e letramento e educação matemática para os docentes de 
$9^{\circ}$ ano. Esse fenômeno de procura por pós-graduação sem relação direta com a área de atuação pode estar associada a dois fenômenos: o primeiro e imediato diz respeito aos planos de cargos, carreiras e salários dos entes federados (estados e municípios) que preveem promoção salarial para os que cursam especialização; o segundo, pode estar relacionado a baixa oferta por cursos específicos nas áreas citadas por parte das instituições de ensino superior, dificultando o acesso por parte desses sujeitos.

No que diz respeito às ações de formação continuada disponibilizadas aos docentes nos últimos dois anos da aplicação do Questionário, 87,1\% do $5^{\circ}$ ano e $80,6 \%$ do $9^{\circ}$ ano afirmaram ter participado, enquanto $89,2 \%$ dos docentes do $5^{\circ}$ ano e $81,7 \%$ do $9^{\circ}$ ano afirmam que quase sempre utilizam os conhecimentos adquiridos na formação continuada para melhoria da sua prática em sala de aula. Nos dois casos, observa-se que os professores do $9^{\circ}$ ano estão em desvantagem em relação aos do $5^{\circ}$ ano. Dados relativos às condições e situação trabalhista são apresentados no Quadro 4.

\section{Quadro 4 - condições e situação trabalhista dos professores participantes da prova Brasil 2011}

\begin{tabular}{|l|c|c|c|c|}
\hline Em quantas escolas você trabalha? & $\mathbf{5}^{\circ}$ ano & $\mathbf{0}$ & $\mathbf{9}^{\circ}$ ano & $\mathbf{\%}$ \\
\hline Apenas nesta escola & 62.863 & $63,8 \%$ & 68.901 & $54,0 \%$ \\
\hline Em 2 escolas & 32.882 & $33,4 \%$ & 49.077 & $38,4 \%$ \\
\hline Em 3 escolas & 2.010 & $2,0 \%$ & 7.940 & $6,2 \%$ \\
\hline Em 4 ou mais escolas & 820 & $0,8 \%$ & 1.774 & $1,4 \%$ \\
\hline Total & 98.575 & $100,0 \%$ & 127.692 & $100,0 \%$ \\
\hline $\begin{array}{l}\text { Qual é a sua situação trabalhista nesta } \\
\text { escola? }\end{array}$ & $5^{\circ}$ ano & $\%$ & $9^{\circ}$ ano & $\%$ \\
\hline Estatutário & 63.447 & $65,6 \%$ & 84.986 & $67,7 \%$ \\
\hline CLT & 8.371 & $8,7 \%$ & 6.839 & $5,4 \%$ \\
\hline $\begin{array}{l}\text { Prestador de serviço por contrato } \\
\text { temporário }\end{array}$ & 17.993 & $18,6 \%$ & 27.307 & $21,7 \%$ \\
\hline Prestador de serviço sem contrato & 1.048 & $1,1 \%$ & 1.027 & $0,8 \%$ \\
\hline Outras & 5.849 & $6,0 \%$ & 5.460 & $4,3 \%$ \\
\hline Total & 96.708 & $100,0 \%$ & 125.619 & $100,0 \%$ \\
\hline
\end{tabular}


Enquanto 63,8\% dos professores de $5^{\circ}$ ano trabalham apenas numa escola, nos docentes de $9^{\circ}$ ano esse valor é reduzido para $54,0 \%$, o que revela que $46,0 \%$ dos professores deste ano atuam em mais de um estabelecimento de ensino. No que se refere à situação trabalhista, chama a atenção o número de docentes com contrato temporário, sendo que no $9^{\circ}$ ano esse valor corresponde a mais de $1 / 5$ dos professores nessa situação e no $5^{\circ}$ ano a $18,6 \%$.

\section{CUMPRIMENTO DE CONTEÚDOS CURRICULARES}

No que diz respeito ao cumprimento dos conteúdos curriculares previstos para o $5^{\circ}$ e $9^{\circ}$ ano, os dados apresentados no Quadro 5 mostram informações referentes aos que responderam a questão.

\section{Quadro 5 - conteúdos curriculares previstos/desenvolvidos pelos professores participantes da prova Brasil 2011}

\begin{tabular}{|l|c|c|c|c|}
\hline $\begin{array}{c}\text { Quanto dos conteúdos previstos } \\
\text { você conseguiu desenvolver com } \\
\text { os alunos desta turma? }\end{array}$ & $\mathbf{5}^{\circ}$ ano & $\mathbf{\%}$ & $\mathbf{9}^{\circ}$ ano & $\mathbf{\%}$ \\
\hline Menos de 40\% & 2.566 & $2,6 \%$ & 2.867 & $2,3 \%$ \\
\hline Entre 40\% e 60\% & 11.300 & $11,7 \%$ & 17.765 & $14,4 \%$ \\
\hline Entre 60\% e 80\% & 42.462 & $43,8 \%$ & 60.512 & $49,0 \%$ \\
\hline Mais de 80\% & 40.658 & $41,9 \%$ & 42.416 & $34,3 \%$ \\
\hline Total & 96.986 & $100,0 \%$ & 123.560 & $100,0 \%$ \\
\hline
\end{tabular}

A análise dos dados permite constatar que $11,7 \%$ dos docentes do $5^{\circ}$ ano informam que conseguiram desenvolver entre $40 \%$ e $60 \%$ dos conteúdos previstos, enquanto no $9^{\circ}$ ano, $14,4 \%$ alancaram essa faixa. Na faixa de $60 \%$ a $80 \%$ dos conteúdos, são $43,8 \%$ do $5^{\circ}$ ano e $49,0 \%$ do $9^{\circ}$ ano que afirmam cumprir, enquanto na faixa acima de $80 \%$ são $41,9 \%$ do $5^{\circ}$ ano e $34,3 \%$ do $9^{\circ}$ ano. Esses dados, se considerarmos o processo cumulativo do não cumprimento de conteúdos curriculares propostos para cada série do ensino fundamental, geram uma significativa parcela de conteúdos suprimida, provocando lacunas cognitivas que podem vir a representar sérias dificuldades de aprendizagem dos conteúdos subsequentes, fazendo o aluno chegar ao $9^{\circ}$ ano com sérios déficits curriculares. 


\section{DIFICULDADES ASSOCIADAS ÀS CONDIÇÕES DE TRABALHO DOCENTE}

No que diz respeito às dificuldades de aprendizagem relacionadas às condições de trabalho e salário dos professores, duas questões mostram dados significativamente diferentes para os professores do $5^{\circ}$ e $9^{\circ}$ anos (Quadro 6). No que tange aos problemas de aprendizagem dos alunos e sua relação com a sobrecarga de trabalho dos professores, $40,7 \%$ dos docentes do $9^{\circ}$ ano concordam que essas duas variáveis estão associadas, enquanto 29,5\% dos professores de $5^{\circ}$ ano concordam com a relação.

\section{Quadro 6 - dificuldades de aprendizagem e sobrecarga de trabalho dos} professores participantes da prova Brasil 2011

\begin{tabular}{|l|c|c|c|c|}
\hline $\begin{array}{l}\text { Relacionam-se a sobrecarga } \\
\text { de trabalho dos professores } \\
\text { dificultando o planejamento e } \\
\text { o preparo das aulas }\end{array}$ & $\mathbf{5}^{\circ}$ ano & $\mathbf{0}$ & $\mathbf{9}^{\circ}$ ano & $\mathbf{\%}$ \\
\hline Concordo & 28.926 & $29,5 \%$ & 51.778 & $40,7 \%$ \\
\hline Discordo & 69.267 & $70,5 \%$ & 75.521 & $59,3 \%$ \\
\hline Total & 98.193 & $100,0 \%$ & 127.299 & $100,0 \%$ \\
\hline
\end{tabular}

A questão salarial é também tema indagado no questionário e o Quadro 7 mostra que enquanto $27,8 \%$ dos professores de $5^{\circ}$ ano associam os problemas de aprendizagem dos alunos ao baixo salário que recebem, $37,5 \%$ do $9^{\circ}$ ano pensam da mesma forma, o que representa $34,9 \%$ a mais de professores deste ano.

Quadro 7 - dificuldades de aprendizagem e salário dos professores participantes da prova Brasil 2011

\begin{tabular}{|l|c|c|c|c|}
\hline $\begin{array}{l}\text { Ocorrem devido ao baixo } \\
\text { salario dos professores, que gera } \\
\text { insatisfação e desestimulo para a } \\
\text { atividade docente }\end{array}$ & $\mathbf{5}^{\circ}$ ano & $\%$ & $\mathbf{9}^{\circ}$ ano & $\%$ \\
\hline Concordo & 27.208 & $27,8 \%$ & 47.513 & $37,5 \%$ \\
\hline Discordo & 70.581 & $72,2 \%$ & 79.207 & $62,5 \%$ \\
\hline Total & 97.789 & $100,0 \%$ & 126.720 & $100,0 \%$ \\
\hline
\end{tabular}




\section{DIFICULDADES ASSOCIADAS A FATORES EXTERNOS À ESCOLA}

Os docentes consideram que grande parte das dificuldades relacionadas à aprendizagem dos alunos está associada a fatores extraescolares, como o ambiente em que vivem, para $83,0^{\%}$ do $5^{\circ}$ ano e $80,9 \%$ do $9^{\circ}$ ano, e o nível cultural dos pais, para $75,1 \%$ do $5^{\circ}$ ano e $73,0 \%$ do $9^{\circ}$ ano. Essa percepção é mais intensa nos professores do $5^{\circ}$ ano do que do $9^{\circ}$ ano e embora grande parte dos docentes veja esses como fatores que comprometem a aprendizagem dos alunos, essa associação deve ser vista com cautela e não podemos "estabelecer uma relação direta, e de certo modo mecânica, entre diferentes variáveis para a determinação desses fatores" (INEP, 2006, p. 172). No entanto, é perceptível a desresponsabilização que estes assumem diante do baixo rendimento escolar dos estudantes.

Ainda sobre as dificuldades de aprendizagem dos alunos, os dados apresentados no Quadro 8 mostram que cerca de 46\% dos docentes de ambos os anos afirmam que estão relacionadas à falta de aptidão e habilidade do próprio aluno, 65,9\% e 69,7\% dos professores do $5^{\circ}$ e $9^{\circ}$ anos respectivamente associam a baixa autoestima do estudante; $87,0 \%$ e $94,3 \%$ dos docentes do $5^{\circ}$ e $9^{\circ}$ ano relacionam os problemas de aprendizagem dos alunos ao desinteresse e falta de esforço dos mesmos e $64,8 \%$ e $73,1 \%$ desses docentes relacionam os problemas de aprendizagem a indisciplina dos alunos em sala de aula.

Quadro 8-dificuldades de aprendizagem e problemas dos alunos para professores participantes da prova Brasil 2011

\begin{tabular}{|l|c|c|c|c|}
\hline $\begin{array}{l}\text { Ocorrem devido à falta de } \\
\text { aptidão e habilidades do aluno }\end{array}$ & $\mathbf{5}^{\circ}$ ano & $\mathbf{0}$ & $\mathbf{9}^{\circ}$ ano & $\mathbf{\%}$ \\
\hline Concordo & 45.224 & $46,1 \%$ & 59.203 & $46,6 \%$ \\
\hline Discordo & 52.778 & $53,9 \%$ & 67.928 & $53,4 \%$ \\
\hline Total & 98.002 & $100,0 \%$ & 127.131 & $100,0 \%$ \\
\hline $\begin{array}{l}\text { Estão vinculados a baixa } \\
\text { autoestima dos alunos }\end{array}$ & $\mathbf{5}^{\circ}$ ano & $\mathbf{0}$ & $\mathbf{9}^{\circ}$ ano & $\mathbf{\%}$ \\
\hline Concordo & 64.687 & $65,9 \%$ & 88.752 & $69,7 \%$ \\
\hline Discordo & 33.489 & $34,1 \%$ & 38.543 & $30,3 \%$ \\
\hline Total & 98.176 & $100,0 \%$ & 127.295 & $100,0 \%$ \\
\hline
\end{tabular}




\begin{tabular}{|l|c|c|c|c|}
\hline $\begin{array}{l}\text { Ocorrem devido ao desinteresse } \\
\text { e falta de esforço do aluno }\end{array}$ & $\mathbf{5}^{\circ}$ ano & $\mathbf{0}$ & $\mathbf{9}^{\circ}$ ano & $\mathbf{\%}$ \\
\hline Concordo & 85.407 & $87,0 \%$ & 119.898 & $94,3 \%$ \\
\hline Discordo & 12.809 & $13,0 \%$ & 7.291 & $5,7 \%$ \\
\hline Total & 98.216 & $100,0 \%$ & 127.189 & $100,0 \%$ \\
\hline $\begin{array}{l}\text { São decorrentes da indisciplina } \\
\text { dos alunos em sala de aula }\end{array}$ & $\mathbf{5}^{\circ}$ ano & $\mathbf{0}$ & $\mathbf{9}^{\circ}$ ano & $\mathbf{\%}$ \\
\hline Concordo & 62.657 & $63,8 \%$ & 93.077 & $73,1 \%$ \\
\hline Discordo & 35.534 & $36,2 \%$ & 34.301 & $26,9 \%$ \\
\hline Total & 98.191 & $100,0 \%$ & 127.378 & $100,0 \%$ \\
\hline
\end{tabular}

Estudo realizado por Davis et al (2012) mostra que há diferenças entre os anos iniciais e finais do ensino fundamental que não podem ser ignoradas, entre elas a faixa etária da população que o frequenta. Nas séries finais os alunos encontram-se na faixa etária de 11 e 14 anos período em que são vivenciadas muitas mudanças dentro e fora da escola, e por isso, é importante o professor aprender a lidar com as alterações corporais da puberdade, com o início do amadurecimento da mente, com a sensibilidade à flor da pele e respeitar a valorização das relações e interações entre jovens.

\section{PARA FINALIZAR}

Os dados apresentados e analisados neste artigo mostram diferenças entre as percepções dos docentes de $5^{\circ}$ e $9^{\circ}$ anos do ensino fundamental acerca de fatores que podem ser associados aos resultados de aprendizagem dos alunos em avaliações de larga escala. A partir das diferenças nas respostas observadas entre os professores de $5^{\circ}$ e $9^{\circ}$ anos, constata-se que docentes do $9^{\circ}$ ano parecem identificar com menor intensidade relação entre o seu próprio trabalho docente e elementos que se articulem aos problemas de aprendizagem de seus alunos.

Os docentes deste ano escolar, embora em pequenas percentagens, são mais jovens do que os do $5^{\circ}$ ano, 46,0\% trabalham em mais de uma escola e 21,7\% possuem contrato temporário de trabalho. Para 40,7\% deles, suas condições de trabalho interferem sobre as dificuldades de aprendizagem dos alunos, no entanto, são os próprios alunos, os grandes responsáveis pelos problemas de aprendizagem com destaque para falta de aptidão (46,6\%), baixa autoestima $(69,7 \%)$, desinteresse e falta de esforço $(94,3 \%)$ e indisciplina $(73,1 \%)$. 
O que se poderia concluir de tais afirmações? Que os docentes não se reconhecem como agentes da gestão de aprendizagem de seus alunos? É possível. O fato é que em não reconhecendo seu próprio protagonismo, os docentes renunciam a um papel que deles é esperado, pelo menos como mediadores do processo de ensino-aprendizagem. Esta é uma questão a ser melhor aprofundada pela política e pela gestão educacional. Do mesmo modo, merece ser incorporada à reflexão sobre a formação inicial e continuada de professores como um desafio para a formulação de novas políticas.

Os dados obtidos por Davis et al (2012) constatam que as políticas públicas concebidas para o ensino fundamental focalizam prioritariamente os dos anos das séries iniciais, não havendo maiores preocupações com as necessidades de alunos e professores das séries finais. É perceptível também uma ruptura na rotina escolar dos anos iniciais para os anos finais, que, por ser uma fase de grandes mudanças no desenvolvimento cognitivo, emocional, social e moral dos alunos, exige distintos modelos de organização no atendimento a essas necessidades. Poder-se-ia afirmar que os dados evidenciados pelas autoras, associadas às constatações apontadas por Davis et al (2012) são os responsáveis pela frustação do efeito onda esperado para o Ideb do $9^{\circ}$ ano?

Essa discussão está apenas começando, uma vez que as séries finais do ensino fundamental não têm sido objeto das políticas educacionais recentes, a exemplo das séries iniciais e ensino médio; situa-se na confluência de dois momentos complexos da vida escolar - passagem da infância para a puberdade e desta para a adolescência - perpassa pela falta de identidade e muita vezes, infraestrutura da escola para atender esses alunos e enfrenta um perfil de formação profissional docente que foi forjado nas instituições de ensino superior para atuar no ensino médio.

\section{REFERÊNCIAS}

ALAVARSE, Ocimar Munhoz; MACHADO, Cristiana; BRAVO, Maria Helena; Políticas educacionais, avaliação de sistema e melhoria da qualidade na educação básica: experiências de dois municípios paulistas. EccoS Revista Científica, núm. 31, mayo-agosto, 2013, pp. 191-205. Universidade Nove de Julho, São Paulo, Brasil. Disponível em: <> Acesso em: 10 ago. 2014.

BARRIGA, Ángel Diaz. A avaliação na educação mexicana: excesso de programas e ausência da dimensão pedagógica. Sísifo - revista de ciências da educação, n. ${ }^{\text {o }}$ 9, Avaliação em Educação: Perspectivas Ibero-Americanas. Mai/ Jun/Jul/Ago, p.19-30, 2009. Disponível em: <http://dialnet.unirioja.es/servlet/ articulo?codigo $=3044846>$ Acesso em: 22 ago. 2014 . 
BRASIL. DOU. Portaria Ministerial no 931 de 21 de março de 2005. $N^{\circ}$ 55, 22/03/05, Seção 1, p. 17. Disponível em: http://download.inep.gov.br/ educacao_basica/prova_brasil_saeb/downloads/Port931_21 MAR05.pdf. Acesso em: 31 jan. 2015.

BRASIL. INEP. Ideb. Índice de Desenvolvimento da Educação Básica - Apresentação. Disponível em: <http://portal.mec.gov.br/index. php?Itemid=336> Acesso em: 10 ago. 2014.

BRASIL. MEC/INEP. Desempenho dos alunos na Prova Brasil: diversos caminhos para o sucesso educacional nas redes municipais de ensino. PARANDEKAR, Suhas D; OLIVEIRA, Isabel de Assis Ribeiro de; AMORIM, Érica (orgs.). Brasília: Instituto Nacional de Estudos e Pesquisas Educacionais Anísio Teixeira, 2008a.

BRASIL. MEC/INEP. Melhores práticas em escolas de ensino médio no Brasil. Brasília, 2010.

BRASIL. Presidência da República. Casa Civil. Subchefia para Assuntos Jurídicos. Lei no 12.527, de 18 de novembro de 2011. Disponível em: < http:/ / www.planalto.gov.br/ccivil_03/_ato2011-2014/2011/lei/112527.htm> Acesso em: 31 jan. 2015.

BROOKE, Nigel. O futuro das políticas de responsabilização educacional no Brasil. Cadernos de Pesquisa. v. 36, n. 128, p. 377-401, maio/ago. 2006. Disponível em: <http://www.scielo.br/ pdf/cp/v36n128/v36n128a06.pdf> Acesso em: 10 ago. 2014.

BROOKE, Nigel. Responsabilização educacional no Brasil. V. 1. n.1 2008. Revista Iberoamericana de Evaluación Educativa. Disponível em:http://www.rinace. net/ riee/ numeros/vol1-num1/art7_htm.html> Acesso em: 10 ago. 2014.

BROOKE, Nigel; CUNHA, Maria Amália de A. A avaliação externa como instrumento de gestão educacional nos estados. Universidade Federal de Minas Gerais. 2010.

CARDOSO, Ana Paula Lima Barbosa. Politicas de educação inclusiva em tempos de IDEB: escolarização de alunos com deficiência na rede de ensino de Sobral. Fortaleza: Universidade Estadual do Ceará. Dissertação de Mestrado, 2011. Disponível em: www.uece.br.ppge>. Acesso em: 07 ago. 2014. 
CASASSUS, Juan. Uma nota crítica sobre a avaliação estandardizada: a perda de qualidade e a segmentação social. Sísifo - revista de ciências da educação, n. ${ }^{0}$ 9, Avaliação em Educação: Perspectivas Ibero-Americanas. Mai/Jun/Jul/ Ago, 2009, p. 71-78. Disponível em: < http://dialnet.unirioja.es/servlet/ articulo?codigo $=3044854>$ Acesso em: 22 ago. 2014 .

CERDEIRA, Diana Gomes da Silva; ALMEIDA, Andréa Baptista de. Os efeitos da política de avaliação e responsabilização educacional na rede pública do Rio de Janeiro. $36^{\mathbf{0}}$ Reunião Anual da ANPEd. Goiânia, 29 de setembro a 02 de outubro de 2013. Disponível em: <http://36reuniao.anped.org.br/pdfs_ trabalhos_aprovados/gt14_trabalhos_pdfs/gt14_3062_texto.pdf> Acesso em: 10 ago. 2014.

COELHO, Maria Inês de Matos. Vinte anos de avaliação da educação básica no Brasil: aprendizagens e desafios. Ensaio: aval. pol. públ. Educ., Rio de Janeiro, v. 16, n. 59, p. 229-258, abr./jun. 2008. Disponível em: < http://www.scielo.br/pdf/ ensaio/v16n59/ v16n59a05.pdf> Acesso em: 10 ago. 2014.

DAVIS, Claudia Leme Ferreira; TARTUCE, Gisela Lobo B. P.; NUNES, Marina Muniz Rosa; ALMEIDA, Patrícia C. Albieri de; SILVA, Ana Paula Ferreira da; COSTA, Beatriz Souza Dias de Olival; SOUZA, Juliana Cedro de. Anos finais do Ensino Fundamental: aproximando-se da configuração atual. Fundação Carlos Chagas (FCC). Estudos \& Pesquisas Educacionais. n 3, 2012, p.103-193. Disponível em: <http://www.fvc.org.br/pdf/desafios-dos-anos-finais-ensinofundamental-alta-relatorio-final.pdf $>$ Acesso em: 19/03/2013.

DERMATINI, Zeila de B. Magistério primário: profissão feminina, carreira masculina. Cadernos de Pesquisa. São Paulo, n. 86, p. 5-14, ago. 1993. Disponível em: <http://www.fcc.org.br/ pesquisa/publicacoes/cp/arquivos/892.pdf> Acesso em: 21 abr. 2014.

DRABACH, Nadia Pedrotti \& FREITAS, Suellem Raquel de. Diretores das escolas públicas brasileiras: quem são esses sujeitos? IX ANPEd Sul. 2012. Disponível em:http://www.ucs.br/etc/conferencias/index.php/anpedsul/9anpedsul/ paper/viewFile/1328/134

FRANCO, Creso; ALVES, Fátima; BONAMINO, Alicia. Qualidade do ensino fundamental: políticas, suas possibilidades, seus limites. Educação \& Sociedade, Campinas, vol. 28, n. 100 - Especial, p. 989-1014, out. 2007. Disponível em: <http://www.scielo.br/pdf/es/v28n100/ a1728100.pdf> Acesso em: 10 ago. 2014. 
FREITAS, Luiz Carlos de. Eliminação adiada: o ocaso das classes populares no interior da escola e a ocultação da (má) qualidade do ensino. Educação \& Sociedade, Campinas, vol.28, n.100, Especial, p. 956-987, out. de 2007. Disponível em: <http://www.scielo.br/scielo. php?script=sci_arttext\&pid =S0101-73302007000300016> Acesso em: 10 ago. 2014 .

INEP/MEC. Relatório Nacional SAEB 2003. Brasília, 2006. Disponível em http://www.publicacoes.inep.gov.br/portal/subcategoria/4. Acesso em 04/02/2015.

INEP/MEC. Saeb 2001 Novas Perspectivas. Brasília, abril de 2002. Disponível em http://www.publicacoes.inep.gov.br/portal/subcategoria/4. Acesso em 04/02/2015;

LOURO, Guacira. Gênero e Magistério: identidade, história, representação. In: CATANI, Denice et alli (orgs). Docência, Memória e Gênero. São Paulo: Escrituras Editora, 1997.

MACEDO, Seandra Doroteu de. Gestão pedagógica em tempos de IDEB. Fortaleza: Universidade Estadual do Ceará. Dissertação de Mestrado, 2011. Disponível em: www.uece.br.ppge>. Acesso em: 07 ago. 2014.

McKINSEY \& COMPANY. Educação - como um sistema escolar de baixo desempenho pode evoluir para tornar-se bom? E como um sistema de bom desempenho pode atingir o nível de excelência? 2007. Disponível em: <http:// www.mckinsey.com/clientservice/Social_Sector/ our_practices/Education/ Knowledge_Highlights/ /media/Reports/SSO/Educa tion_Intro_Standalone_ Nov24_Portugeuse.ashx> Acesso em: 23/01/2013.

McKINSEY \& COMPANY. How the world's best-performing school systems come out on top (Como os sistemas escolares de melhor desempenho do mundo chegaram ao topo). Disponível em: <http://www.mckinsey.com/ locations/UK_Ireland/ /media/Reports/UKI/Educa tion_report.ashx $>$ Acesso em: 13/02/2013.

NARVAES, Andréa Becker \& OLIVEIRA, Vânia Fortes de. Magistério: Profissão Feminina. Disponível em: http://www.portalanpedsul.com.br/ admin/uploads/1999/Formacao_De_Professores/Trabalho/02_04_04_ MAGISTERIO__PROFISSAO_FEMININA.pdf> Acesso em: 21 abr. 2014. 
PEARSON. The education curve-lessons in country performance in education. 2012 Report. Published by Pearson. Developed by the Economist Intelligence Unit. Disponível em: <http://thelearningcurve.pearson.com/> Acesso em: 28/02/2012.

RABELO, Mauro. Avaliação Educacional: fundamentos, metodologia e aplicações no contexto brasileiro. Coleção PROFMAT. Sociedade Brasileira de Matemática. Rio de Janeiro, 2013.

RAVITCH, Diane. The death and life of the great american school system: how testing and choice are undermining education. New York: Basic Books, 2010.

SOUZA, Ângelo Ricardo de. As relações entre os resultados da avaliação e os modelos de gestão escolar. Intermeio - Revista do Programa de Pós-graduação em Educação da UFMS, volume 13, no 25, p. 64-81, jan-jul de 2007. Disponível em: <http://www.intermeio.ufms.br/ revistas/25/Intermeio_25.pdf> Acesso em: 10 ago. 2014.

SOUZA, Sandra Zákia Lian de; OLIVEIRA, Romualdo Portela de. Políticas de avaliação da educação e quase mercado no Brasil. Educação \& Sociedade, Campinas, vol. 24, n. 84, p. 873-895, setembro de 2003. Disponível em: <http:// www.scielo.br/pdf/ es/v24n84/a07v2484.pdf> Acesso em: 10 ago. 2014.

VIANNA, Heraldo Merelin. Avaliações nacionais em larga escala: análise e propostas. Fundação Carlos Chagas. São Paulo: DPE, 2003.

VIDAL, Eloísa Maia \& VIEIRA, Sofia Lerche. Gestão educacional e resultados no IDEB: um estudo de caso em 10 municípios cearenses. Estudos em Avaliação Educacional, vol. 22 n. 50, p. 419 - 434, set/dez 2011. Disponível em: <http:/ / www.fcc.org.br/pesquisa/publicacoes/ eae/arquivos/1658/1658.pdf $>$ Acesso em: 10 ago. 2014.

VIDAL, Eloísa Maia \& VIEIRA, Sofia Lerche. Políticas municipais de educação em tempos de IDEB: um estudo de caso em uma região do Ceará. IV Congresso Ibero-Americano de Política e Administração da Educação. Porto, 2014. Disponível em: <www.anpae.org.br> Acesso em: 07 ago. 2014.

VIEIRA, Sofia Lerche e VIDAL, Eloísa Maia. Estudos \& Pesquisas: contribuições para políticas educacionais - Relatório Final. Fortaleza: Fundação Victor Civita, 2013. Disponível em: <http://fvc.org.br/pdf/relatorio-finalpesquisas-politicas-2.pdf> Acesso em: 10 ago. 2014. 
VIEIRA, Sofia Lerche. Educação Básica: política e gestão da escola. Fortaleza: Liber Livro, 2008b.

VOLANTE, Paulo. Liderazgo instrucional y logro académico em la educación secundaria em Chile. In WEINSTEIN, José y MUÑOZ, Gonzalo. Qué sabemos sobre los diretores de escuela en Chile? Centro de Innovación en Educación de Fundación Chile y Centro de Estudios de Políticas y Prácticas em Educación (CEPPE). 2012. p. 349-367.

WERLE, Flavia Correa Obino. Práticas de gestão e feminização do magistério. Cadernos de Pesquisa. v. 35, n. 126, p. 609-634, set./dez. 2005. Disponível em http://www.scielo.br/pdf/cp/v35n126/a05n126.pdf> Acesso em 21 abr. 2014.

SOFIA LERCHE VIEIRA é doutora em Filosofia e História da Educação pela Pontifícia Universidade Católica de São Paulo (PUC/SP), com estágio de pósdoutorado na Universidad Nacional de Educacion a Distancia (UNED). É docente do Programa de Pós-Graduação em Educação da Universidade Nove de Julho (UNINOVE) e da Universidade Estadual do Ceará (UECE). E-mail: sofialerche@ gmail.com

ELOISA MAIA VIDAL é doutora em Educação pela Universidade Federal do Ceará e professora adjunta da Universidade Estadual do Ceará onde atua também como coordenadora adjunta da Universidade Aberta do Brasil. E-mail: eloisamvidal@ yahoo.com.br

JAANA FLAVIA FERNANDES NOGUEIRA é doutora em Educação pela Universidade da Califórnia, (UCLA) e Técnica em Assuntos Educacionais do Ministério da Educação desempenhando a função de Diretora de Programa da Secretaria Executiva. E-mail: jaanafernandes@gmail.com

Recebido em fevereiro de 2015 Aprovado em março de 2015 